\title{
Alterações na sexualidade da mulher no \\ climatério
}

Osmar Pellegrini Júnior*

\section{RESUMO}

Os distúrbios emocionais da menopausa nem sempre são determinados por alterações do equilíbrio hormonal, freqüentemente a crise da menopausa é agravada por eventos principalmente da esfera social.

A crise da menopausa é maximizada com a sensação de perda de pessoas próximas, esteios do seu equilíbrio emocional.

Espera-se que no ano 2000, uma em cada três mulheres viva três décadas após a menopausa com expectativa de vida por volta de 80 anos. É vital cuidar bem destes anos buscando, a todo custo, o bem estar físico e emocional.

\section{SUMMARY}

Menopausal emotional disturbs not even are caused by hormonal balanced secretions. Mostly the menopausal crisis is increased by social day-life-alterations.

* Médico. Ginecologista e Terapeuta Sexual.

Recebido em 15.07.98

Aprovado em 02.08.98 
The depression caused by the loss of closer relatives or parents mean to be more harmful to the emotional liability than hormonal decreases.

Until the 2000 years more then one third of women will live in post menopausal period until 3 decades after. So we have support conditions in life for them.

\section{INTRODUÇÃO}

A sintomatologia do climatério está diretamente relacionada à perda da função endócrina e reprodutiva, independente do climatério ter sido efetivamente manifesto ou apenas uma tranqüila passagem.

Vários são os fatores que interferem nesta travessia que a mulher faz entre o menacme e senectude. Não são apenas os fenômenos hormonais que podem influenciar no comportamento desta mulher, mas também os fenômenos sócio-culturais e psicológicos. E com base nestes últimos é que iremos tecer comentários.

Quando a mulher está próxima dos 50 anos, é possível que seus pais estejam na casa dos 80 anos, os filhos com cerca de 20 e o marido, no ápice da profissão, passando pouco tempo em casa e diminuindo o suporte conjugal físico e psicológico. Se a mulher não criou os seus próprios interesses começa a se sentir inútil. A reconsideração de valores atua independente dos hormônios, particularmente nas que chegam virgens à menopausa ou naquelas que mantêm o casamento baseado mais no relacionamento com os filhos do que com o marido. A menopausa tem significado próprio para cada mulher, mas para a maioria é símbolo de envelhecimento, muitas pensam que é o fim de todas as sensações e experiências sexuais, criando e vivenciando idéias auto-agressivas. A menopausa representa o fim da procriação, um dos papéis femininos mais importante e gratificante. De modo geral, as pessoas acham feio e não aceitam que a mulher com mais de 50 anos possa namorar, esquecendo que a sexualidade não é só sexo mas toda uma afetividade essencial do ser humano.

\section{COMPORTAMENTO SEXUAL E MENOPAUSA}

Há um decréscimo geral da atividade e prazer sexual com a idade, porém, existe considerável variação individual, dependendo das circuns- 
tâncias. Muitas pessoas mantêm uma atividade sexual satisfatória a relativamente freqüente por volta dos 60 e 70 anos.

Em um trabalho francês, onde se pesquisou estado civil, idade e freqüência de relações sexuais entre homens a mulheres observou-se que $8 \%$ dos homens eram viúvos, divorciados ou separados contra $31 \%$ das mulheres. A atividade sexual nos homens diminuiu pouco até os 65 anos e nas mulheres claramente entre os 52 e os 65 . A proporção de homens sem nenhuma relação sexual no ano anterior passou de $6 \%$ aos 52 anos para $32 \%$ aos 70 anos ao passo que nas mulheres, $16 \%$ aos 52 anos e $73 \%$ aos 70 anos; $40 \%$ dos homens entrevistados afirmaram haver tido uma relação sexual na semana anterior e apenas $26 \%$ das mulheres fizeram tal afirmação. As mulheres deste trabalho se acomodavam bem a essa situação, menos de $20 \%$ desejavam ter relações sexuais mais freqüentes. Das $42 \%$ das mulheres na amostragem que não tinham atividades sexuais somente 1/3 lamentavam a diminuição de tal atividade e somente $36 \%$ se declararam dispostas a realizar um tratamento para melhorar seu comportamento sexual, 5\% relataram sentir menos prazer do que quando mais jovens, $24 \%$ destas atribuiam o desinteresse ou insastifação ao companheiro, $14 \%$ se devia parcialmente a elas mesmas e $60 \%$ inteiramente a elas; $13 \%$ causado pela dispareunia e $50 \%$ por diminuição da libido ou interesse sexual.

Procurando respostas a tais comportamentos na depleção hormonal ovárica que ocorre na menopausa como fator biológico, sabe-se que a carência estrogênica parece favorecer a depleção de neuroaminas em certas áreas celulares, com suspensão da ação frenadora sobre as funções de vigilância. $\mathrm{O}$ aumento da vigilância pode explicar a irritabilidade, insônia, ansiedade e resposta aumentada ao estresse habitual da vida diária. A carência dos mesmos leva a um estado de simpaticotomia: irritabilidade e fatigabilidade aumentadas. Quanto ao estado psicológico, não se encontrou correlação entre os sintomas psicológicos e as concentrações plasmáticas de esteróides sexuais e gonadotrofinas. Porém, a deterioração sexual parece estar associada a uma diminuição dos estrógenos e andrógenos na concentração plasmática. No estudo de menopausa de Stanford, se comprovou uma associação significativa entre a diminuição do estradiol plasmático e irregularidade menstrual, frequência de ondas de calor e o decréscimo da atividade coital. Em pós menopáusicas, a diminuição do estrógeno abaixo de $35 \mathrm{PG} / \mathrm{ml}$ se associou significativa mente a uma freqüência esporádica, menos que semanal, de coito. Sabe-se então que o decréscimo da freqüência coital está relacionado com a diminuição do estrógeno e que a diminuição do desejo sexual com 
a queda da testosterona, segundo Mccoy e Davidson, Leiblum e al. encontraram uma correlação positiva entre a atividade sexual pós-menopáusica e as concentrações plasmáticas de androstenediona e testosterona e FSH e LH porém não de estradiol e estrona. O ovário pós-menopáusico, continua produzindo em seu estroma andrógenos (androstenediona e testosterona). O baixo estímulo de LH e esses andrógenos modulam, possivelmente, a atividade de certos circuitos neuronais do sistema límbico importantes na apetência sexual endógena. As grandes diferenças individuais nessa secreção estromal porém, explicam as variações na manutenção do interesse sexual.

\section{FATORES SÓCIO-CULTURAIS E PSICOLÓGICOS}

\section{Ignorância popular}

Falsas concepções do tipo "já passou o tempo", fazem parte dos conceitos de muitos profissionais da saúde acerca da sexualidade nos indivíduos mais idosos.

\section{Preconceitos sexuais}

- Sexualidade é reprodução: conceito válido no mundo dos animais onde o sexo está a serviço da reprodução. A sexualidade da mulher é necessidade física e psicológica profundamente influenciada pelos padrões da cultura e da sociedade. Poucas pessoas "fazem sexo" apenas para procriar. Na maioria das vezes, a sexualidade é usada como meio de prazer, constituindo-se numa extraordinária forma de comunicação. A reprodução ocorre em certo período da vida, a sexualidade está presente em toda a existência.

- Sexualidade é juventude: a sociedade brasileira glorifica a juventude, e exalta o corpo. A menstruação ainda é insígnia da feminilidade, um símbolo de juventude.

- Sexualidade como consequiência pura dos hormônios ovarianos: a atividade sexual é independente da função ovariana. É claro que sofre influência desta, mas não puramente devida aos hormônios ovarianos. 
- Figura materna e mulher assexuada: a figura da mãe é quase invariavelmente a de uma mulher sábia, conselheira, pura, santa e assexuada, sobretudo se está na menopausa. As reações sexuais da mãe climatérica são consideradas imorais quando, de fato, traduzem um comportamento normal.

\section{DISCUSSÃO}

Homens a mulheres sofrem, com o passar dos anos, o impacto da depleção hormonal. No homem, as mudanças observadas na forma do seu corpo parecem influenciar menos a resposta sexual e o desejo. Com a queda da testosterona, há um decréscimo da atividade sexual, porém esta queda é lenta e, como o fator sóciocultural influencia diretamente sem superestimar as alterações físicas, as repercussões sexuais tornam-se graduais e assimiláveis. Na mulher, há uma queda súbita dos níveis hormonais, mudanças corporais evidentes e presa à juventude, tão enaltecida e exigida pela sociedade, sua auto-estima diminui, tornando-se difícil a atividade sexual permanecer inalterada. $O$ tratamento psicoterapêutico dos transtornos psicosexuais climatéricos torna-se de difícil abordagem, já que a personalidade das pacientes se encontra fragilizada pelo envelhecimento, pelo conflito da perda da função ovárica de solução aparentemente impossível. A relação médico-paciente nestes casos revela-se extremamente difícil.

A psicoterapia para reduzir a ansiedade e depressão não é um objetivo realista e muitas vezes torna-se estressante e de duvidoso êxito final, segundo Wenderlein (1986). Contudo a associação de uma psicoterapia de grupo com reposição hormonal parece oferecer bons resultados porém, nunca deve ser preferida a psicoterapia ao tratamento medicamentoso. Em grande parte dos casos, a primeira medida psicoterapêutica é a prescrição do tratamento medicamentoso e a segunda, de não fazê-la sem estar certo da aceitação e credibilidade da paciente.

A terapia sexual somente está indicada nos casos de disfunção sexual de transtornos climatéricos recentes e na vigência de uma motivação para o tratamento e com um cônjuge ativo e participativo. Se a mulher tinha prazer sexual antes da menopausa, continuará com atividade sexual regular. Não existe motivo científico que comprove que a relação sexual não possa ser satisfatória como antes. $\mathrm{O}$ corpo da mulher tende a permanecer erótico e erotizável durante toda vida. 
É importante reiterar que o organismo, com o passar dos anos, modifica-se como um todo e a sexualidade também se transforma. A resposta erótica na mulher idosa não é menor do que na jovem, é apenas diferente, pois os anos podem reduzir a força, mas jamais bloquear o desejo ou anular a resposta.

\section{CONCLUSÃO}

O climatério provoca involução dos órgãos reprodutivos, carência de hormônios, redução do estímulo e da intensidade sexual, porém:

- não há limite de idade para o desempenho sexual nos níveis de resposta orgásmica;

- a mulher idosa é inteiramente capaz do desempenho sexual nos níveis de resposta orgásmica;

- a vida sexual no climatério depende, essencialmente, da experiência vivencial pregressa;

- tudo depende de um organismo saudável e de um parceiro interessante e interessado.

O grande problema da sexualidade na mulher no climatério é a sua própria reação psicológica frente as pressões sociais. O problema surge quando ela própria passa a acreditar que é tarde demais para o sexo.

\section{REFERÉNCIAS BIBLIOGRÁFICAS}

1. COLLINS, A.; HANSON, V.; ENEROTH, P. et. al. Psycological stress responses in postmenopausal women before and after replacement therapy. Hum. Neurobiol. 1982, 1:153-157.

2. SAAB, Pg.; MATTHEWS, Ka.; STONEY, CM.; MCDONALD, Rh. Premenopausal and postmenopausal Women differ in their cardiovascular and neuro-endocrine responses to behavioral stresses. Psychoneuroendocrinology. 1989, 26:270-280.

3. HALLSTROM, T. Sexualidad en el climaterio. Obstet. ginecol.: temas actuales. 1977, 4:231-243.

4. DELIGNIERES, B.; WEILLI, Mauyais-Jarvis P. et. al. Relations interactives comportements sexuels et hormono-therapic substitutive postmenopausique:enquete sofres. Rev. Franc Ginecol obstet. 1990, 85:581-586. 
5. CUTLER, Wb.; GARCIA, Cr. e MCCOY, N. Perimenopausal sexuality. Arch sex behav. 1987, 16:225-234.

6. WENDERLEIN, J. M. Psychosocial aspects in the perimenopause in green blatt $\mathrm{Rb}$ and Heithecker R.. A modern approach to the perimenopausal years. Gruyter, Berlin-New York, 1986, pp. 87-92.

7. YOUNG, G. R. L.; KUMAR, N. S. and GOLDZIER, J. W. Management of menopause when estrogens cannot be used. Drugs. 1990, 40:220-230

8. DOMINIAN, J. Psiquiatria y menopausia. Clin obstet. gynecol. Ed. Esp. Abril 1977, pp. 245-262. 